\title{
Entre o virtual e o concreto: um olhar sobre os entrecruzamentos de expectativas e realidades vividas no estágio curricular obrigatório para a conclusão de um curso de Licenciatura em Letras
}

\author{
Marianna Collares Soares Rego ${ }^{1}$
}

\begin{abstract}
Resumo
Este trabalho tem como objetivo apresentar um relato de experiência baseado nas vivências de uma acadêmica do curso de Letras Português/Inglês durante seu estágio curricular obrigatório em um Instituto Federal na região sul do Brasil. Busca-se, também, enfatizar a importância do diário de bordo - teacher's journal - como escrita, que propiciou reflexões sobre o ser e o fazer docentes e que, posteriormente, repercutiram na constituição da identidade profissional da pesquisadora em questão. Como de praxe, os estágios obrigatórios para conclusão de cursos de graduação constituem-se como espaços para que os sujeitos em formação possam simular o porvir e, neste caso específico, para desenvolver atividades de ensino de língua inglesa concatenadas com a realidade dos estudantes, com foco em tarefas que os colocassem como indivíduos ativos no processo de aprendizagem dessa língua estrangeira. Desse modo, espera-se que esta narrativa possa ecoar e ajudar aqueles que trabalham em prol de uma aula de língua inglesa mais eficiente.
\end{abstract}

Palavras-Chave: Ensino de Inglês; Estágio Curricular; Identidade Docente.

\begin{abstract}
This paper aims to present the experiences of an undergraduate student during her compulsory practicum at a federal institution in South Brazil. This narrative shed light on the importance of the written record of the prospective English teacher's daily classroom practices - teacher's journal - to the construction of her professional identity. As usual, the compulsory practicum in under graduation courses are likely to be developed in spaces where the pre-service teachers experience real learning situations. Specifically, this pre-service teacher sought to develop activities connected to the students' context in order to engage them actively in a collaborative and communicate learning environment. In conclusion, it is expected that this narrative may resound and help those who work for evolving more efficient English lessons.
\end{abstract}

Keywords: English Teaching; Compulsory Practicum; Teaching Identity.

\section{Introdução}

Na constituição do sujeito-docente, muitas vozes se entrelaçam, desde questões socioculturais até a triangulação entre o que pode ser chamado - em analogia à psicanálise de "professor sonhado", "professor idealizado" e "professor real". Nesse sentido, pode-se afirmar que as vivências da graduação - e, neste caso, do momento de realização dos estágios curriculares em que, de fato, o graduando se depara com o front de batalha objetivam instrumentalizar teoricamente o professor-estagiário para o porvir. Mesmo assim,

\footnotetext{
${ }^{1}$ Graduada em Letras Português/Inglês pela Universidade Federal do Rio Grande (FURG) e Mestranda em
} Estudos da Linguagem do Programa de Pós-Graduação em Letras (FURG).

LínguaTec, Instituto Federal de Educação, Ciência e Tecnologia do Rio Grande do Sul, Bento Gonçalves v. 3, n. 1, p. 143-157, jun. 2019. 
são sabidos os conflitos e o grau novidadeiro que a prática da sala de aula - que assusta e encanta - adquire nesse período de estágio.

Com base nessas ideias, este texto tem como objetivo compartilhar com a comunidade acadêmica as reflexões de uma estudante de graduação em Letras em fase de conclusão de curso, especificamente no momento de seu estágio curricular. Pretende-se, com isso, não apenas dialogar com aqueles que têm a intenção se aventurar em cursos de Letras, mas também com pesquisadores que se dedicam a pesquisar estratégias de incrementar os processos educativos.

Para dar conta de cumprir este objetivo, este texto assume características do gênero relato de experiência, em que a professora-estagiária adquire voz para descrever suas expectativas, projeções, sensações e, quiçá, frustrações. Assim, o texto se organiza em seis seções, que vão desde a reflexão inicial sobre o ser professor até a exposição das etapas que compõem o estágio curricular proposto pela universidade a que se filia. Espera-se, dessa forma, acrescentar a perspectiva humana na constituição do profissional.

\section{SOBRE SER PROFESSOR: tópicos de leituras das aulas de Linguística Aplicada}

Ao considerar o contexto de formação, é verdadeiro afirmar que, durante os primeiros anos do curso de licenciatura em Letras Português/Inglês, a maior parte das atividades destinaram-se a instrumentalizar o professor em formação com o dito conhecimento "concreto". Em função disso, as disciplinas tiveram seu foco aplicado ao estudo das teorias literárias e aos aspectos morfossintáticos não só da língua materna (LM), como também da estrangeira (neste caso, de língua inglesa). No entanto, os questionamentos sobre identidade docente começaram a emergir para além das fundamentações teóricas estudadas desde o início do curso de licenciatura. Segundo Duarte (2014), essas identidades não existem a priori, tampouco são fixas; desse modo, os sujeitos as constituem a partir do seu olhar sob e pelo outro e, em consequência disso, o professor de língua estrangeira (LE) em formação, em especial, pode transitar entre "ser apenas um aprendiz de língua inglesa (LI)", "ser um professor em processo de aprendizado de LI" ou "não ser nem um professor, nem um aprendiz de LI". Nesse sentido, o primeiro passo na 
construção do "eu-professor" perpassa pela compreensão do papel da língua inglesa na sociedade pós-moderna; assim, é importante salientar que, aqui, entende-se língua sob a perspectiva sociointeracional (MARCUSCHI, 2008), como mecanismo de comunicação o qual é flexível aos diferentes contextos sócio-histórico-culturais.

Sob essa perspectiva, os estudos em Linguística Aplicada (LA), desde a década de 1990, vêm se desenvolvendo com o objetivo de compreender o papel não só da língua inglesa, como também do professor de língua estrangeira em uma sociedade globalizada. Por esse viés, Kumaravadivelu (2006) pontua que a fase atual da globalização tem diminuído as distâncias espacial e temporal, isto é, a vida dos indivíduos passa por mudanças sem que as percebam ou que as controlem; e tem corroborado para o desaparecimento das fronteiras de informação, ou seja, os ideais, as culturas e os valores vêm sendo compartilhados com tamanha facilidade através do avanço tecnológico que nos aproxima, cada vez mais, de outras realidades. Diante disso, a língua inglesa é considerada a "língua da globalização" e/ou língua franca, pois, com o crescimento da comunicação eletrônica a partir da internet, especialmente das mídias sociais, oportuniza um maior acesso às diferentes comunidades linguísticas. Tal fato colabora para que os efeitos atinjam não só a intercomunicação entre grandes esferas - a saber, o impacto do American Way Of Life ao redor do mundo -, como também o contexto escolar.

Nesse sentido, espera-se que o professor de língua inglesa seja capaz de se adaptar aos diferentes núcleos escolares aos quais será exposto. Segundo Leffa (2016), existe um perfil do "professor como ele deveria ser", ou seja, o ensino de uma língua estrangeira exige determinadas qualidades, "umas mais óbvias que as outras" (p. 72). Para além do domínio das estruturas dessa língua, abordagens, metodologias e técnicas de ensino, há traços desejáveis de personalidade desse docente, como: paciência, flexibilidade, mente aberta, tolerância, entre outros. Além desses traços, o autor enfatiza três aspectos que se referem ao aprofundamento das características psicológicas desejáveis: 1) criatividade, 2) intuição e 3) paixão. No que tange ao primeiro item, destaca-se que:

Um artista não precisa de muita coisa para criar uma obra prima - às vezes nada mais do que um cinzel, um martelo e um bloco de pedra. Às vezes, quanto menos se tem, melhor é a obra, que pode sair mais densa e enxuta. Na sala de aula, 
portanto, podemos definir criatividade como a capacidade de explorar os recursos limitados de que se dispõe para criar um número ilimitado de condições de aprendizagem. (LEFFA, 2016, p. 74)

A partir da relação entre ensino e arte, compreende-se que se pode considerar o bom professor aquele que baliza suas demandas e seus objetivos e, com isso, reconhece suas limitações, mas não se prende a elas. Além disso, ser criativo não significa fugir de atividades que visem à centralidade do professor em sala de aula. Ser criativo, então, relaciona-se ao reconhecimento de que, na maioria das vezes, os poucos recursos não podem conter a vontade de criar e de ensinar, porque, enquanto houver uma sala de aula cheia de alunos, sempre existirá um novo mundo de aprendizados. Em relação ao segundo traço, enfatiza-se que:

\begin{abstract}
Podemos definir intuição como a capacidade de fazer conexões; quanto mais conexões se fizer, mais intuição se tem. De certa maneira, a intuição implica a habilidade de reconstruir dentro de nós o mundo externo, de modo a maximizar nossas relações com este mundo. A habilidade de se adaptar às circunstâncias, de perceber as relações entre aspectos teóricos e o que acontece na sala de aula, de identificar num conjunto complexo de variáveis aquela que pode influir na aprendizagem de um determinado traço linguístico são, a meu ver, indícios da intuição. (LEFFA, 2016, p. 77)
\end{abstract}

É sabido que o ensinar uma língua estrangeira vem se transformando, pois o acesso à informação faz que a tecnologia, às vezes, mostre-se mais "adaptável" às necessidades do aluno. O professor, cuja intuição é determinada como importante na elaboração das aulas, visualiza aos questionamentos sobre o futuro da língua, já que a aprendizagem parece estar a apenas um clique de distância. Desse modo, é essencial identificar essa complexidade e aliar as atividades aos novos recursos disponíveis, de forma intuitiva, para a aprendizagem ser eficiente. Cabe ainda considerar a variável paixão, sobre a qual se pode pontuar que:

O segredo da paixão é que ela afeta os sentimentos das pessoas e por isso as envolve. As pessoas não aprendem se não forem envolvidas. A ideia do envolvimento como pré-requisito da aprendizagem vem de longe, aparentemente da Antiga China, provavelmente de Confúcio:

Diga-me e eu esqueço

Ensina-me e eu lembro

Envolva-me e eu aprendo. (LEFFA, 2016, p. 79-80) 
No mais, essa característica pode ser compreendida como a mais profunda das três mencionadas. Trata-se de um sentimento intrínseco ao sujeito-docente, que poderá guiar a prática e alterá-la de dentro para fora. Nesse ínterim, fala-se da habilidade que a paixão por algo tem de mover a si e ao outro, porque o processo de aprendizagem de uma língua deve ser descolado da ideia de que o aluno aprende aquilo que o professor ensina. $O$ estudante procurará, na maioria das vezes, um ambiente confortável que o motive, que o envolva não só na tarefa escolar, mas também em uma nova possibilidade de adquirir conhecimento e de exercer sua cidadania. Certamente, isso será o resultado do trabalho de um docente apaixonado por perceber seus alunos como indivíduos essenciais nessa caminhada.

\section{DIÁRIO DE BORDO: teacher's journal e outros elementos de fomento à reflexão teórico- prática}

Nesta seção, será abordada uma parte específica dos planos de aula escritos pela professora-estagiária não só a fim de contextualizar este relato narrativo, como também fomentar reflexões sobre os impactos desse registro à construção do "eu-docente". Nesse sentido, pode-se considerar esta seção como a portadora do relato da experiência docente vivida no período dos estágios obrigatórios da graduação.

Tem-se, então, que no último ano da graduação, o Estágio Curricular Supervisionado em Língua Inglesa é um dos pré-requisitos à obtenção do diploma; trata-se de uma disciplina anual que contempla não só ministrar aulas de inglês na escola, mas também observar a turma escolhida para o período de estágio, planejar atividades e produzir um relatório final. Nesse primeiro contato de observação, os registros escritos eram opcionais. Ademais, concomitantemente às visitas semanais, aconteciam reuniões com a professora-orientadora e os seus demais orientandos de estágio em uma universidade federal gaúcha.

No caso particular deste relato, os primeiros encontros foram destinados à explicação de como os planos de aula deveriam ser constituídos e, como um requisito metodológico da professora-orientadora, o diário do professor, chamado teacher's journal, constituiu-se como a sétima parte que compõe o planejamento, na qual os professores-estagiários deveriam registrar, de forma breve, aquilo que Ihes chamou a atenção durante a prática. O seu 
principal objetivo era que, através da reflexão escrita, os acadêmicos conseguissem fazer uma auto-avaliação do seu desenvolvimento enquanto sujeitos-docentes, além de colaborar à elaboração das atividades seguintes. Acredito que a escrita do teacher's journal assumiu uma grande importância na formação do professor-estagiário, já que nesse espaço foi possível relacionar os objetivos com a turma às expectativas que foram criadas durante essa fase da graduação além de, principalmente, oportunizar a reflexão sobre momentos da prática que fogem do controle, pois abrangem situações que vão além do que é previsto nos planos de aula.

A realidade observada pela professora-estagiária fomentou outras estratégias de planejamento. Depois das observações, foi decidido que, ao longo do período de estágio, o tema central seriam músicas populares na cultura americana. As temáticas específicas - a saber, os tipos de músicas que foram escolhidos - variaram de acordo com as semanas; somou-se a isso o fato de que, em junho, tinha-se duas datas comemorativas, o Dia dos Namorados e o Dia do Orgulho, nas quais a professora-estagiária trabalhou com músicas de amor e de temática LGBT. Na aula lecionada no dia dos namorados, a atividade final consistiu em os alunos organizarem-se em círculo e, a partir do vocabulário estudado sobre os adjetivos trabalhados nas músicas, os estudantes deveriam mencionar algo que admiravam no colega ao lado. Sobre essa experiência, a professora-estagiária registrou no teacher's journal que:

\begin{abstract}
Eu estava muito entusiasmada sobre a aula, por causa do tema dela [músicas de amor]. Eu amo o dia dos namorados não só por ser um dia romântico, mas também por termos a possibilidade de demonstrar amor àqueles que admiramos (amigos, família, etc). O momento mais bonito da aula foi o final. Nós fizemos um círculo, e um dos alunos me olhou e disse: 'eu não conheço essa garota direito. O que eu posso dizer sobre ela?'. Então, eu respondi dizendo que aquela era a oportunidade para eles se conhecerem. Ele disse, em inglês, que não poderia afirmar o que admirava nela, mas que gostaria de conhecê-la melhor. Às vezes, nós só precisamos parar e prestar atenção nas pessoas maravilhosas que nos rodeiam. ${ }^{2}(S I C)$
\end{abstract}

Dessa forma, pode-se perceber que, mesmo com a similaridade em relação às abordagens adotadas pela professora-regente, o desenrolar das primeiras atividades ainda

\footnotetext{
1-2 Trechos traduzidos do teacher's journal e pela professora-estagiária.

3-4 Trechos traduzidos do teacher's journal e pela professora-estagiária.
} 
surpreendiam a professora-estagiária visto que a complexidade das interações dentro da sala de aula não permite prever as atitudes responsivas dos alunos. Além disso, a tarefa não consistia em "etiquetar" uns aos outros com os adjetivos, mas sim propor que, naquele momento, fosse possível estabelecer reflexões sobre a natureza das relações entre eles, a qual, muitas vezes, passa despercebida.

Nas semanas seguintes, os estudantes continuaram a se engajar nas atividades de fala mais do que o esperado pela professora-estagiária, a qual continuou investindo tanto na Abordagem Baseada em Tarefas quanto em Competências (LEFFA, 2016). Nesse contexto, a metodologia utilizada culminou no relato:

Eu nunca imaginei que pudessem emergir tantas questões gramaticais pertinentes em uma aula como essa, voltada às tarefas que ajudam na compreensão do texto [música]. Utilizei bastante o quadro e eu não esperava isso também. Mas, em específico, duas garotas me chamaram atenção nesta semana, porque elas nunca falaram em aula [durante as minhas observações]. Uma delas me fez perguntas em inglês e a outra apresentou muito interesse em compartilhar sua opinião. ${ }^{2}$ (SIC)

Dessa maneira, foi perceptível que os alunos se sentiram confortáveis quando não só o professor estava preparado para trabalhar de determinada forma, mas também quando existiu a preocupação em engajar a todos, de forma colaborativa, no processo de ensinoaprendizagem. Em função das pequenas tarefas de vocabulário, dos exercícios de comparação entre músicas de um mesmo tema geral, que construiu múltiplos significados, e do compartilhamento das interpretações, criou-se um ambiente confortável para os aprendizes construírem uma nova identidade na sala de aula de língua inglesa.

Com o passar das semanas, a turma foi preparada para a aplicação de uma sequência didática (DOLZ, NOVERRAZ, SCHNEUWLY, 2004; ALMEIDA, 2015) mais longa, a qual se estendeu por duas semanas em sala de aula e resultou em tarefas extraclasse. Dentre elas, a principal atividade consistia em gravar um vídeo, com o celular de, no máximo, cinco minutos e que contasse a história da música escolhida; ainda, que fosse coerente com a análise feita sobre a letra dessa canção. Para que isso ocorresse, esta professora-estagiária preocupou-se em destinar a primeira parte da sequência a apresentar o - Lyric video project. Sobre essa aula, foi registrado em seu teacher's journal: 


\begin{abstract}
Na minha cabeça e no meu planejamento, não era possível que grupo de trabalho algum apresenta-se o desejo de fazer o vídeo sobre uma paródia política. Era muito claro: escolher uma música original em inglês, entender como funcionaria a análise linguística e o que precisava ser definido como tema central e específico para as próximas etapas. Fui surpreendida. Acho que preciso parar de pensar que posso controlar tudo o que vai acontecer em minhas aulas. A complexidade disso me deixa reflexiva. Tudo transcorreu bem, e o jeito como os alunos se relacionaram com as tarefas me surpreendeu. As ideias deles ultrapassaram qualquer expectativa minha. ${ }^{3}(S I C)$
\end{abstract}

Nesse trecho, a professora-estagiária mostra como o comportamento dos alunos frente à determinada exigência pode surpreender até mesmo quando há uma instrução prévia que, para ela, não permitia diferentes perguntas e/ou respostas. O fato ocorrido proporcionou uma nova reflexão, pois uma tarefa classificada como "simples" - a escolha de uma música, por exemplo - despertou a criatividade dos alunos, isto é, foi realizada com o objetivo de dialogar com o contexto no qual se inserem não só na aula de inglês, como também no mundo real.

Em seguida, outras atividades foram realizadas concomitantemente ao final do planejamento e à elaboração do vídeo, que foram finalizados extraclasse. Na aula destinada à apresentação do resultado final para o grande grupo, a professora-estagiária registrou em seu diário de bordo:

Eu gostaria de enfatizar que, de longe, essa foi a minha aula favorita. Primeiro, eu fiquei muito emocionada porque estamos chegando na reta final dessa experiência. Nós assistimos aos seus vídeos e nos divertimos muito. Eles verdadeiramente se engajaram no projeto e produziram trabalhos maravilhosos! Sabia da mobilização deles, mas não esperava que tomasse grandes proporções a ponto de convidarem outras pessoas para participarem disso. ${ }^{4}(S I C)$

Em relação a sensação de "dever cumprido" que permaneceu depois das apresentações, salienta-se que isso só ocorreu porque os alunos protagonizaram esse momento, mostrando-se proativos para o trabalho em grupo, bem como para coletivamente produzir algo que envolvesse a utilização de novas habilidades em um suporte que sua geração já domina. Além disso, os estudantes buscaram inserir pessoas do entorno, o que refletiu o desejo de criarem algo significativo ao todo, exercitando sua cidadania e criticidade; assim, o resultado desse projeto superou as expectativas desta professora- 
estagiária porque, em situações anteriores, como docente e em observações, vivenciou práticas que não a possibilitaram ultrapassar os limites da sala de aula - naquele momento de epifania do registro escrito, as identidades se entrecruzaram. Ainda, esse foi um dos momentos que confrontou a máxima, recorrente nos discursos do senso comum, de que "a língua inglesa não funciona na escola pública".

Então, ao assumir a identidade de professora de LE em formação, considera-se que a reflexão sobre a prática se torna essencial durante todos os momentos dentro e fora da sala de aula, uma vez que o estágio em Língua Inglesa foi a primeira experiência direta com a escola, com os alunos e com o conjunto complexo de fatores externos que podem influenciar o andamento das atividades. Dessa maneira, o teacher's journal tornou-se uma ferramenta de auxílio, pois possibilitou refletir sobre as diferentes metodologias de aprendizagem estudadas ao longo da graduação, que podem resultar em uma aula de LI mais ou menos eficiente.

\section{CONTEXTO DE PESQUISA: sobre a acolhida na sala de aula}

Nesta seção, será apresentada a sala de aula que recebeu a professora-estagiária; tal informação se faz relevante no sentido de contextualizar este relato de experiência docente com a realidade que se encontra ao chegar à escola pública - neste caso, de domínio federal. Saliente-se que a escolha da escola em que o estágio deve ocorrer cabe ao estagiário e, nesse caso, a opção por esse estabelecimento se deu em função de haver vínculo afetivo com tal núcleo escolar, local de onde essa professora-estagiária é egressa. Ainda, nesta seção também discorrer-se-á acerca do período de observações, quando não só esteve previamente com a turma, como também foi realizada uma reunião com a professoraregente, a fim de construir um planejamento coerente com aquele contexto de ensino.

Nesses termos, é fato que um contexto escolar totalmente diferente em relação às escolas públicas estaduais/municipais foi encontrado pela professora-estagiária: como se trata de uma instituição federal, localizada no centro da cidade do Rio Grande/RS, que oportuniza a formação técnica concomitantemente ao ensino médio (EM), a disciplina de Língua Inglesa só existe no primeiro ano. Em função disso, a fim cumprir a carga horária 
legalmente prevista para a disciplina no EM, os alunos têm duas horas/aula, ou seja, dois períodos de uma hora-relógio cada no mesmo dia da semana. Mesmo assim, o que inicialmente pareceu assustador - duas horas inteiras de aula com uma mesma turma! - logo se transfigurou em uma maior possibilidade de trabalho com atividades que, às vezes, tornar-se-iam mais difíceis de realizar em períodos menores. Assim, com o objetivo de se familiarizar não só com a turma, como também com o tempo de aula, a professora-estagiária escolheu observá-los por todo o mês de maio, quando foi possível delimitar, mesmo que hipoteticamente, quais recursos proporcionariam uma aula mais eficiente. Vale salientar, ainda, que o grupo era composto por 24 alunos, com faixa etária entre 16 e 18 anos. A maioria dos alunos mostrou-se engajada nas atividades propostas pela professora-regente, as quais se relacionavam tanto às atividades escritas quanto de compreensão de textos; quando eram questionados a elaborar exemplos em inglês, apresentaram certa resistência, pois afirmavam "não saber falar direito".

Ademais, a professora-regente comentou sobre o livro didático da escola e enfatizou razões pelas quais não o utilizava. Entre elas, estava principalmente o fato de que os exercícios não contemplavam temáticas pertinentes e que fossem além do domínio das estruturas da língua; a professora-regente mostrou-se aberta a diferentes propostas que poderiam ir ou não ao encontro do que ela já tinha trabalhado, logo, sua flexibilidade foi de extrema importância para que o diálogo continuasse ao longo de toda a prática.

Assim, comprovando a máxima de que confronto com o novo costuma despertar receio nos indivíduos nos primeiros contatos, existiu uma polarização entre o que o grupo esperava da nova professora e a expectativa que ela criou sobre eles. Dessa forma, entre reflexões e novos planejamentos, foi possível criar um denominador comum que satisfez ambas as partes que, em algumas semanas, já encontraram a sintonia de trabalho. Em outras palavras, é verdadeiro afirmar que, apesar do receio pelo novo, mesmo que a abordagem tenha se mantido semelhante à da professora-regente, poucas semanas foram suficientes para encontrar um ritmo próprio de trabalho e proporcionar momentos significativos com a turma não só no que se tem estabelecido como relação professor-aluno, mas também no que os alunos trouxeram nas suas bagagens para a sala de aula. Um exemplo disso foi o fato de que, quando os estudantes foram questionados a escolher uma música com a qual se 
identificavam, puderam justificar suas escolhas a partir das próprias experiências de vida e suas relações sociais; logo, trouxeram para sala de aula reflexões não só sobre a influência da cultura inglesa no cotidiano, mas também sobre como puderam se redescobrir por meio dela.

\section{E AGORA? JÁ SOU PROFESSORA?}

Durante a trajetória entre o planejar e o pôr em prática, dúvidas como as do título desta seção tornaram-se constantes. Existiu - e, provavelmente, sempre existirá - o lado desta professora-pesquisadora que também é constantemente aprendiz, o que entra em conflito com a identidade docente que vem sendo construída. Nesse sentido, é importante que o professor-estagiário, sobretudo, compreenda seu papel e se permita transitar por essa experiência reconhecendo-se efetivamente como professor.

Para as práticas que foram narradas ao decorrer deste relato, o foco no uso do aparelho celular delineou-se, especialmente, a partir dos estudos ao longo do curso de graduação, que proporcionaram diversas reflexões sobre o impacto do aprendizado de língua inglesa através de recursos que acompanham esse "novo mundo" dos alunos; no entanto, entre o planejado e as condições reais de realização, a professora-estagiária precisou reorganizar as atividades, visto que a instituição não contava com acesso à internet dentro das salas de aula. Foi, então, quando, em meio às cobranças e às expectativas, os alunos mostraram uma saída: alguns deles possuíam internet móvel e dispuseram-se a compartilhar com os outros colegas. Sobre esse posicionamento dos alunos, apontou-se que:

\footnotetext{
Uma aula estática é uma impossibilidade teórica. Se existisse, seria o desespero do professor e o fracasso da educação. Os alunos entrariam na escola e dela sairiam sem nada terem aprendido. O que provoca a mudança, e consequentemente a aprendizagem, é a interação entre os elementos que compõem o sistema. (LEFFA, 2009, p. 16)
}

Dessa forma, pode-se perceber que a ação colaborativa fez parte daquele grupo e que a cooperação abre portas para que nos percebamos no outro à medida que também se aprende quando se ajuda alguém. Além disso, durante as aulas, foi essencial reconhecer que 
os estudantes sentiam necessidade de ser protagonistas daquele espaço; por isso, as atividades começavam guiadas pela professora-estagiária mas, na maioria das vezes, visavam a um resultado em que os papeis fossem alternados, e ela pudesse proporcionar a visibilidade que eles tanto desejavam.

Por outro lado, um dos maiores desafios foi guiar a aula em língua inglesa. Nas primeiras aulas, falar em inglês o tempo todo, que é considerado o "ideal" por alguns métodos, gerou um estranhamento nos alunos; apesar de ser importante a imersão no contato com a língua, sob determinada perspectiva, foi preciso ponderar o que melhor funcionava para aquela turma. Por isso, ao longo das 10 semanas, que resultaram em 20 aulas ministradas, adaptações foram feitas e a professora delimitou os momentos destinados ao falar em inglês, o que resultou em um maior engajamento dos alunos. No mais, existiram diferenças, sim, entre o esperado pela professora-estagiária e o que realmente foi feito; tais fatos colaboraram para que se confirmasse o papel do professor como mediador. Dessa forma, cabe a ele instigar e motivar os alunos a saírem de sua zona de conforto, respeitando as diversas formas de aprender de cada um. Compreendeu-se, também, que os desafios no ensino de uma língua estrangeira se fazem presentes em diferentes contextos, tanto no que diz respeito ao que o próprio docente projeta como uma adversidade quanto no que os contextos escolares apresentam.

\section{CONSIDERAÇÕES FINAIS}

A partir deste relato de experiência, espera-se que essa voz possa ecoar e alcançar não só aqueles que cursam Letras, mas também os que pretendem se aventurar no mundo docente. $O$ entrecruzamento do que se entende como ser professor permite transitar entre o orgulho e a frustração, de maneira a parecer que a sala de aula se transforma em uma montanha russa.

Em relação à organização desta narrativa, destinou-se a segunda seção a discorrer sobre os tópicos de leituras das aulas de Linguística Aplicada, a fim de delimitar o campo de estudos no qual me insiro enquanto professora-pesquisadora. Por isso, acredita-se que o ensino de língua inglesa deve pautar-se na transgressão de fronteiras (MOITA LOPES, 2006), 
principalmente as teórico-metodológicas, pois o processo de ensino-aprendizagem extrapola o domínio de recursos linguísticos específicos ao considerarmos o caráter dialógico e social da linguagem.

Na terceira e quarta seções, visou-se a apresentar não só sobre do que se trata o teacher's journal, mas também qual é o seu impacto no (re)planejamento das atividades elaboradas e na reflexão sobre o "eu-docente"; ainda, delineou-se o contexto de pesquisa com o intuito de enfatizar os discursos que ajudaram a alcançar o objetivo final proporcionar práticas eficazes para o ensino de inglês dentro de um Instituto Federal. $\mathrm{Na}$ quinta seção, buscou-se dialogar com os desafios apresentados durante o estágio, como o desenvolver toda a aula em língua inglesa. Pode-se verificar, também, que, às vezes, os alunos responderam às tarefas propostas de modo inesperado, mas isso não deve ser interpretado negativamente. Os professores, em especial, estagiários, podem se sentir "fracassados" dentro da sala de aula, entretanto, pretendeu-se mostrar que essas reformulações das/nas práticas - entre o idealizado previamente e o contexto escolar real vêm ao encontro do que é defendido nesta narrativa: o fato de que o professor nunca está "acabado" ou é "detentor" de um saber homogêneo e inalterável, mas sim que se encontra em eterno processo de construção didática e identitária.

Sobre o contexto de ensino técnico-tecnológico, a elaboração das atividades foi ao encontro do que as Orientações Curriculares Nacionais para o Ensino Médio (2006) intitulam como diretrizes básicas para as aulas de línguas estrangeiras, as quais devem promover as práticas de letramento para além do ensino elementar das funções da linguagem. Dessa forma, esse cenário tecnológico que é agente promotor do desenvolvimento do aluno não só pelo viés pessoal, como também profissional simultaneamente, reorienta o papel do professor de inglês para que, a partir dessas práticas, mostre ao estudante que sua formação técnica não se dá à parte da aprendizagem de outra língua, pois os processos se cruzam e se complementam quando os aprendizes são capazes de constituir um posicionamento crítico frente à realidade em que se inserem.Assim, as metodologias apresentadas nesta narrativa visaram à promoção, através da Língua Inglesa, do "adquirir consciência da natureza social e ideologicamente construída das formas específicas que habitamos e usamos em determinados momentos" (STREET, 2014, p. 15), o que se acredita contribuir diretamente em 
suas futuras experiências profissionais tanto ao longo do curso técnico quanto após serem inseridos no mercado de trabalho.

Portanto, frente à fase final do curso de graduação, o estágio curricular tornou-se a porta de entrada efetiva para a sala de aula. As expectativas eram altas, já que não se tinha passado por uma experiência assim ao longo do curso. No mais, reitera-se que a relação aluno-professor precisa, cada vez mais, ser permeada por afeto, pois, a partir dele, conseguiremos proporcionar um ambiente confortável para a troca de saberes, sejam eles em língua inglesa ou em outros aspectos sociais que envolvem a aprendizagem.

\section{Referências}

ALMEIDA, A.C.P. De Brás Cubas à curva de Koch: produção textual com base nas teorias da Complexidade. 2015. Doutorado em Linguística Aplicada - Programa de Pós-graduação em Letras, Universidade Católica de Pelotas.

BRASIL. Secretaria de Educação Básica. Ministério da Educação. Orientações Curriculares para o Ensino Médio - Linguagens, códigos e suas tecnologias. Brasília, 2006. Disponível em: http://portal.mec.gov.br/seb/arquivos/ pdf/book_volume_01_internet.pdf. Acesso em:23 mar. 2019.

DOLZ, J.; NOVERRAZ, M.; SCHNEUWLY, B. Sequências didáticas para o oral e escrita: apresentação de um procedimento. In: Gêneros orais e escritos na escola. (Org.) Roxane Rojo e Glaís Sales Cordeiro. Campinas: Mercado de Letras, 2004.

DUARTE, B.G. Professores em formação de inglês: complexidade, escala de valores $e$ identidades. 2014. Mestrado em Linguística Aplicada - Programa de Pós-graduação em Letras, Universidade Federal de Pelotas.

KUMARAVADIVELU, B. Understanding language teaching: from method to postmethod. New Jersey: LEA, 2006.

LEFFA, V. J. Língua estrangeira. Ensino e aprendizagem. Pelotas: EDUCAT, 2016.

LEFFA, V. J. Se mudo o mundo muda: ensino de línguas sob a perspectiva do emergentismo. Revista Caleidoscópio. v. 7, n. 1, p. 24-29, jan/abr 2009.

LONGARAY, E. A. A aprendizagem de inglês na escola pública no Brasil e o mito da importância da língua estrangeira. Brasília: EM ABERTO, 2009. v. 22. no 81. p. 47-59. 
MARCUSCHI, L. A. Produção textual, análise e gêneros e compreensão. São Paulo: Parábola, 2008.

MOITA LOPES, L. P. (Org.). Por uma Linguística Aplicada Indisciplinar. São Paulo: Parábola Editorial, 2006.

STREET, B. Letramentos Sociais: abordagens críticas do letramento no desenvolvimento, na etnografia e na educação. São Paulo: Parábola Editorial, 2014.

Data de submissão: 24/04/2019. Data de aprovação: 19/05/2019. 